\title{
Analysis of the Quality of Vet Qualifications in Albanian Qualifications Framework
}

\author{
Ejvis (Shehi) Gishti \\ National Agency for Vocational Education, Training and Qualifications, Albania
}

\begin{abstract}
.
Quality assurance is one of the most critical elements of any qualifications framework. According to (ETF, 2016) there is a significant difference between the quality assurance of qualification providers and the quality assurance of qualifications. It represents a challenge because all qualifications have to be assured of quality before they can be included in NQF, but it is precisely this obligation that is also a major strength of the qualifications frameworks. After all, this belief serves one of the main purposes of qualifications: "to allow people to use their knowledge, skills and competencies in different environments in the world of learning and work" (ETF, 2011). Qualifications frameworks and qualifications are usually benchmarks for quality assurance, but in most countries, quality assurance systems continue to focus on the capacity of providers to provide quality education, rather than on processes related to the development and use of qualifications. However according to (ETF, 2011) there are a number of areas in which we can see a clear role that qualifications frameworks have in quality assurance. This research provides an analysis of vocational qualification quality allocated in Albanian Qualifications Framework. The analysis identifies issues on how existing qualifications respond to five elements of the qualification cycle: (i) Relevance of the qualification for the labour market; (ii) Standards on which the qualification is based; (iii) Learning process; (iv) Assessment; and (v) Certification., and as well as draws some recommendations to address these issues.
\end{abstract}

Key words: vocational qualifications, qualification framework, quality, standards.

\section{Introduction}

The development and implementation of NQFs has been a tool to review quality assurance mechanisms. According to Gordon (2007) qualification systems are under pressure for: (i) develop coherent paths of progress for individuals to move vertically to a higher level of qualification; (ii) improve access to learning opportunities and further qualifications to develop their knowledge, skills and competencies, to improve market integration opportunities; (iii) develop flexibility to allow young people and adults who have dropped out of school; (iv) ensure transparency between different types of degrees and / or certificates that exist in each country, so that individuals can more easily enter the highest level qualifications or specialists; (v) establish criteria and procedures to ensure the quality of qualifications that may be issued 


\section{3rd International Conference on Modern Research in EDUCATION, TEACHING AND LEARNING}

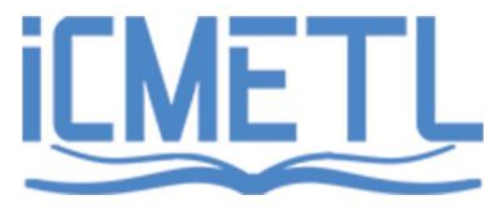

20 - 22 August 2021

Dublin, Ireland

by the ministry or various bodies; and (iv) improve the links between learning and the labour market in order to ensure the relevance of the qualifications offered.

According to (ETF, 2016) there is a significant difference between the quality assurance of qualification providers and the quality assurance of qualifications themselves. Quality assurance is one of the most critical elements of any qualifications framework. It represents a challenge because all qualifications have to be assured of quality before they can be framed, but it is precisely this obligation that is also a major strength of frameworks. If stakeholders and end users of qualifications can be convinced of the effectiveness of quality assurance processes related to the framework, this will greatly increase the market value of qualifications. After all, this belief serves one of the main purposes of qualifications: "to allow people to use their knowledge, skills and competencies in different environments in the world of learning and work" (ETF, 2011). In this respective it is very important to have relevant qualifications, competent qualifications providers and a valid and objective student's assessment process of acquired knowledge, skills and competencies. To achieve and maintain trust regarding the importance and value of qualifications, all stakeholders need to be involved in an accountable and transparent manner, not only designing process, but also in the implementation stages.

Albanian Qualifications Framework (AQF) is being implemented since 2010. It has a structure of 8 levels. Vocational Education and Training (VET) is represented in AQF levels from 2-5. To be included in the AQF, qualifications will have to meet certain quality criteria such as meeting labour market and social demands. Making decisions about which qualifications are to be included into the AQF requires an overview of the qualifications currently existing in Albania.

\section{Research methodology}

Albanian Qualifications Framework is the instrument for a quality system of qualifications in the country. The purpose of qualification quality analysis is to provide information on elements of the qualification quality cycle. This analysis focuses on the importance of qualifications for the labour market, the involvement of labour market actors in different stages of the qualification process and the relevant institutional definition. The main research question examines what are the main features related to the quality and relevance of qualifications.

For obtaining information through focus groups, group discussions were designed with a semistructured structure for experts. It was important during the discussion to identify as clearly as possible what were their expectations on the quality of qualifications of the most important abovementioned aspects of the quality of qualifications in VET. In this paper the focus group was used as the main qualitative method. Measures were taken for the success of the focus group sessions, in such a way that:

$>$ Focus the discussion on the topic;

$>$ Apply semi-structured interviews so that the topics are addressed in each group.

$>$ Create space and opportunity for everyone individually to express their opinion.

$>$ Motivate and encourage interaction within the group. 
Focus group participants

In the framework of the analysis of the qualifications quality in the VET system in Albania, 5 focus groups were held with the participation of public institutions (teachers from vocational schools / university lecturers) as well as representatives of the labour market in the country.

25 experts were engaged in these focus groups. The selection of experts was made possible by applying a random selection from the population of 150 experts engaged at the institution for implementing Albanian Qualifications Framework in VET. Each meeting was organized in groups of 5 participants by "stakeholders" and 1 moderator, the author of this paper. In each focus group a 2: 3 or 1: 4 ratio was maintained between "stakeholders" from the "teaching process in vocational education" and "stakeholders" from the labour market, where 1-2 participants were experts from schools / universities and 3- 4 participants were experts from the labour market.

Structural analysis was used to analyse the data through focus groups and interviews (Srivastava $\&$ Thomson, 2009). The steps taken to realize data analysis through this approach (Srivastava \& Thomson, 2009) are: (i) familiarity with transcripts; (ii) identification of topics; (iii) indexing; (iv) creating tables; and (v) creating map and interpreting.

The aim of implementing the qualitative method of structural analysis was to create results, which are orienting and allow interpretation not only by researchers, but also by persons interested in the topic, and serve to draft recommendations at the central and local level.

\section{Findings/Results}

The individual aspects identified as "core elements" by the structural analysis of the semi structured focus group questions (according to Annex 1) and the discussions are identified. However, the sequence of "basic elements" does not suggest that one indicator is more important than the other. In the discussion, several drafts of quality cycle were combined as responses to aspects often overlapped with others. In evaluating the draft impact indicators, the need arose to reorganize and / or combine aspects of the quality.

The results of the "map" generated by the structural analysis of the collected data of the focus groups of experts engaged are presented in the following figure: 
Dublin, Ireland

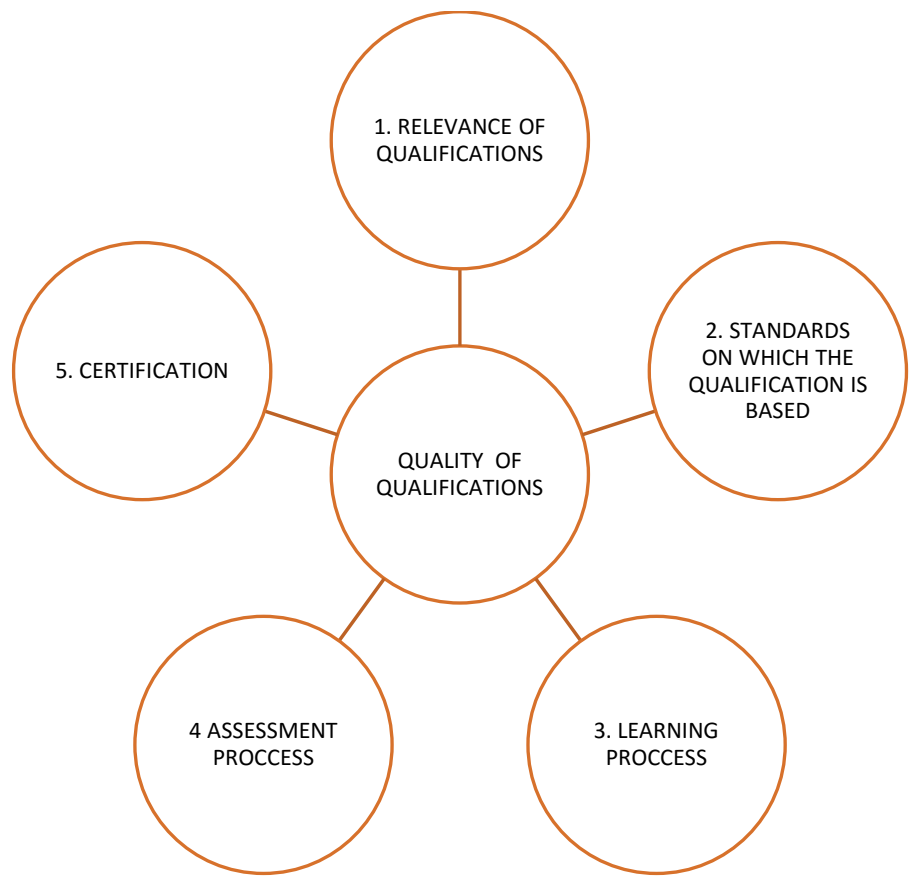

Figure 1. Map of structural analysis

The results of the structural analysis of the focus groups of experts engaged identified the following 5 aspects / sections for the analysis of the qualifications quality.

I. Relevance for the labour market. In VET system, there is a coherent policy cycle of internal and external processes for the development and maintenance of vocational qualifications allocated in AQF, which supports the relevance of the qualifications for the labour market. The analysis of labour market, by using different methods and tools in identifying skills/occupations needed in the labour market is the basis to start the mechanisms for designing new qualifications or updating the existing ones in VET. Meanwhile, NAVETQ develops and maintains the list of occupations since 2009. Up to date, 666 occupations descriptions are developed. The occupation descriptions are designed in cooperation with social partners and professional experts, in most of the cases following standardised methods, such as DACUM method.

II. Standards and structure. The National Catalogue of Vocational Qualifications developed by NAVETQ is de facto the register of vocational qualifications in Albania and is recently approved by the Minister in charge of VET. It includes both: (i) occupational descriptions/standards and qualification descriptions which represents the standards of vocational qualifications described in learning outcomes. 
Dublin, Ireland

Currently, 122 vocational qualification descriptions / standards have been developed, all accessible online. The vocational qualifications development process goes through an internal and external quality assurance system to verify if a qualification fits the respective AQF level and reflects the competencies demanded by the labour market.

A qualification description/standard is the basis for the development of a national frame curriculum for that qualification. NAVETQ is the institution responsible for the development of the national frame curricula for each vocational qualification, which is approved by the Minister in charge for vocational education. NAVETQ issues as well the principles and assessment criteria for summative assessment for certification.

III. Learning process. Qualifications allocated in AQF are provided mainly by public vocational education providers. A frame curriculum is mostly organized in subjects for theory part and in modules for practical part including compulsory professional practice modules and elective professional practice modules. Curriculum for general subjects is developed by the Institute for Education Development and is expressed in learning objectives and general themes. The frame curriculum serves as a guide for VET to develop the school level curricula leading to vocational qualifications.

Vocational qualifications are primarily provided on a school-based approach. The main target group include youngsters in full-time education. Vocational qualifications contain as well practical modules, which are totally outcome-based, meaning that the implementation could be both in school workshops and/or at the workplace, depending on businesses' preparedness to host VET students. There are some examples of school-business cooperation, which are based on Cooperation Agreements that specify the responsibilities of the school, the company and the student.

IV. Assessment process. Formative and summative students' assessment in VET usually refers to official instructions and guidelines. The frame curricula offer recommendations on how to verify the proficiency of learning outcomes of a qualification. NAVETQ provides also different guidelines for VET teachers and providers with assessment methods and assessment tools (such as tests, projects, control check list, etc.). VET providers are responsible for assessment and certification of vocational qualifications at the AQF levels 2, 3, 4 and 5. Summative assessment of learning outcomes for the purpose of certification is organised at the provider level through exams that assess separately the vocational theory and practice. Teachers are responsible for this assessment based on their observation, tests, homework, projects and other assessment techniques. Usually, providers create a commission for each of the two exams (professional theory and practice); by assuming that for the practical exam one of the members of the commission should be from the businesses, but you can find only few cases of such an involvement. The examination can include evaluation of projects, assessment at the workstations, or a combination of these. Unfortunately, regulations and guidelines do not 


\section{3rd International Conference on Modern Research in EDUCATION, TEACHING AND LEARNING}

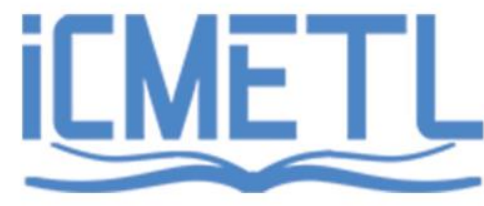

20 - 22 August 2021

Dublin, Ireland

guarantee fair and valid assessment of practical skills leading to a trusted qualification. Nor do they guarantee that the world of work is involved in the assessment.

V. Certification. Students after successfully accomplishing the final examinations will be awarded with the vocational certificate and respective supplement for each AQF level. Students, who have achieved a certificate at the AQF level 4, are eligible to take part in the Professional State Matura exams. The summative exams for the Professional State Matura are centrally organised by Ministry of Education, and the successful students will be awarded with Professional State Matura Diploma.

\section{Conclusions and Recommendations}

Closely related to the assessment of learning is also a very important aspect of standardization in education, especially in VET. Standards provide opportunities: to regulate the content of learning in accordance with the goals of education and the needs of the labor market; to improve the control over the level of preparation and, consequently, to increase its quality; to ensure the coherence of education levels, the convertibility of education, both inside and outside the country.

The gap between existing qualifications and the most demanded occupations needs to be addressed through a structured translation process from occupations to relevant qualifications for all the AQF levels. The role of employers in development, delivery and assessment of vocational qualifications is problematic but crucial and needs urgent attention. New forms of delivery of vocational qualifications are introduced such as work based learning where the learner spends considerable time of the learning process at business premises. This can only be realised with broad commitment of employers to participate actively in vocational education. The establishment of the sector committees will also have an added value for developing occupational standards and validating standards and qualifications related documents, which are currently missing in VET sector.

The study shows a positive attitude and expectations for what the AQF offers in the quality of qualifications, taking into account the fact that the opinions of the actors involved in the study are also influenced by previously developed practices for the development and implementation of traditional qualifications derived from "fully state driven" processes of designing qualifications. This is also confirmed by the literature according to which "The validity of any professional qualification depends on the involvement of all stakeholders; the less involved the actors, the lower the value and credibility in the labor market of the qualifications in question "(ETF, 2016, p. 49).

The AQF should foster trust among the various stakeholders so that they can have confidence in the integrity of the resultant framework and give relevant contribution on it. It is crucial to make qualifications system more transparent and qualifications more users friendly. Thus, a 
communication strategy on spreading trust in and knowledge of the AQF in Albania, should accompany the journey towards developing and implementing an AQF that will support the modernization of the education and training system in Albania.

\section{References}

1. CEDEFOP. (2008) the shift to learning outcomes - Conceptual, political and practical developments in Europe, Study Paper.

2. Gordon, J. (2007, unpublished). Referenced in Leney, T. (2009). Qualifications that count: strengthening the recognition of qualifications in the Mediterranean area. Torino: ETF.

3. CEDEFOP (2011), Development of national qualifications frameworks in Europe.

4. ETF. (2011). Implementation arrangements for national frameworks of qualifications and the role of stakeholders and institutions.

5. ETF. (2016). Qualifications systems: Getting organized.

6. http://www.akafp.gov.al/lista-kombetare-profesionale/

7. http://www.akafp.gov.al/dokumente-kurrikulare/skelet-kurrikula-te-arsimit-te-mesemprofesional/

8. http://www.akafp.gov.al/programe-orientuese-matura-2014/

9. http://www.akafp.gov.al/lista-kombetare-e-profesioneve/

10. http://www.akafp.gov.al/vleresimi-dhe-certifikimi/udhezues-per-vleresimin-enxenesve-ne-ap/

11. http://www.akafp.gov.al/rreth-nesh/baza-ligjore/

12. http://www.vet.al/ 
Dublin, Ireland

\section{Appendices I}

\section{FOCUS GROUP ORIENTATION QUESTIONS MODEL}

Short presentation.

General questions

$\checkmark$ How are the relevance / linkage of this qualification to the labour market / employment ensured? Are labour market actors involved in defining training needs for this qualification?

$\checkmark$ What types of standards are behind the qualifications and what is the interconnection with curriculum development?

$\checkmark$ Does the learning process ensure the achievement of learning outcomes, and moreover are labour market actors involved in the learning process for this qualification

$\checkmark$ How the assessment processes ensure the verification and acquirement of learning outcomes? What is the assessment based on and which are the types of assessments

$\checkmark$ Which is the quality assurance confirmation of the Qualification? 